\title{
Obesity and the Demand for Canadian Physician Services
}

\author{
James McIntosh \\ Economics Department, Concordia University, Montreal, Canada \\ Email: James.mcintosh@concordia.ca
}

Received 5 September 2014; revised 22 October 2014; accepted 6 November 2014

Copyright (C 2014 by author and Scientific Research Publishing Inc.

This work is licensed under the Creative Commons Attribution International License (CC BY). http://creativecommons.org/licenses/by/4.0/

c) (†) Open Access

\section{Abstract}

The objective of this study is to determine the role that obesity plays in how often Canadians visit their family doctors or general practitioners. Doctor visits are analyzed using mixtures of ordered probability models applied to sample survey data from the 2010 Canadian Community Health Survey. This procedure is shown to be superior in terms of likelihood criteria to the more usual one involving count models of doctor visits. The main result is that obesity is one of the leading causes of doctor visits. Obesity has become more important in the demand for physician services than smoking for all Canadians. Other factors including diabetes, the individual's level of education, position in the income distribution, and drinking behavior are also important. The application of latent class's ordered probability models by age-group and gender leads to results which are different from what others have found. While obesity is shown to be a serious problem in Canada, it has not yet reached the stage which some researchers have described as critical.

\section{Keywords}

Obesity, Doctor Visits, Latent Class Models, Two Part Count Models

\section{Introduction}

The weight of Canadians has increased enormously over the last three decades. For the thirty year period 19782008 a recent report on obesity produced by two Canadian health agencies [1] has shown that the proportion of Canadians aged at least 18 who are obese has increased from $14 \%$ to $25 \%$. This is a remarkable and alarming change in human physiology. Concerns arise because obesity is associated with diabetes for both children and adults, with heart disease, with some forms of cancer, stroke, and with a large number of other ailments. The report mentioned above also noted that illnesses associated with obesity cost the Canadian economy an amount somewhere between 4.6 and 7.2 billion dollars per year in 2001. Longitudinal studies from several countries 
show high personal costs as well. At age forty, [2] using data from the Framingham heart study, showed that non-smoking males and females lost 5.8 and 7.1 years of life expectancy, respectively because of their obesity.

The purpose of this project is to analyze the determinants of doctor visits using data from the 2010 Canadian Community Health Survey [3]. While some attention has been focused on the associations between obesity and heart disease and diabetes, the effect of obesity on the actual utilization of the various services that are provided by Canada's health care system have not been adequately examined by Canadian health researchers. Unlike some of the studies that have been carried out using recent European and American data, there is only one study of doctor visits for Canada which examine the impact of this country's obesity problems on the demand for access to family doctors and general practitioners ${ }^{1}$. There are several Canadian studies which examine general practitioner utilization rates [5] [6], but these do not consider the effects of obesity on doctor visits.

\section{Data}

The data comes from the 2010 Canadian Community Health Survey which is a representative random sample of Canadians who were contacted by Statistics Canada by telephone. The data used here are publicly available to all Canadian academic users. The survey focuses on health issues but there is a very good selection of demographic variables which describes the respondent's socioeconomic position as well as detailed information on smoking behavior, alcohol and recreational drug use. Excluding respondents who failed to reveal their weight and height, the frequency of their doctor visits, and those less than twenty years of age or had a BMI of less than 15 , left a sample of 23,755 males and 28,400 females. The total sample survey size is 62,909 and most of the exclusion are due to age. The distributions of visits by BMI category and gender are shown in Table 1.

Demographic variables include education, income, the diseases from which they suffer, age, and the level of physical activity. There are five educational categories: less than secondary school graduation, secondary school graduation, some post-secondary education, a post-secondary educational qualification and missing. The residual category is post-secondary school graduation. Income is measured by the respondent's decile in the income distribution. There are six smoking categories: daily smoker to a never smoker which is the residual category. There are three alcohol use categories; regular drinker, occasional drinker, and non-drinker which is the residual category ${ }^{2}$. Three diseases are included; these are diabetes, heart disease, and a group of other serious disease like

Table 1. Doctor visits by BMI category, age group, and gender.

\begin{tabular}{|c|c|c|c|c|}
\hline & $15-24.99$ & 25 - 29.99 & $30-34.99$ & $35+$ \\
\hline \multicolumn{5}{|c|}{ BMI Category Males } \\
\hline \multicolumn{5}{|c|}{ Age Group } \\
\hline $20-29$ & 1.529 & 1.511 & 1.537 & 1.949 \\
\hline $30-39$ & 1.799 & 1.690 & 2.228 & 2.412 \\
\hline $40-49$ & 1.962 & 2.220 & 2.696 & 3.375 \\
\hline $50-59$ & 2.387 & 2.482 & 3.060 & 4.066 \\
\hline $60+$ & 3.250 & 3.316 & 3.792 & 4.246 \\
\hline \multicolumn{5}{|c|}{ BMI Category Females } \\
\hline $20-29$ & 3.108 & 3.777 & 4.152 & 4.704 \\
\hline $30-39$ & 2.853 & 3.378 & 3.627 & 4.508 \\
\hline $40-49$ & 2.725 & 3.233 & 4.092 & 4.288 \\
\hline $50-59$ & 2.869 & 3.359 & 3.691 & 4.599 \\
\hline $60+$ & 3.360 & 3.650 & 4.167 & 4.756 \\
\hline
\end{tabular}

\footnotetext{
${ }^{1}$ The study by [4] finds a strong positive relation between being obese, which they define as having a BMI greater than 27 and a qualitative measure of physician visits.

${ }^{2}$ It would have been desirable to have a distinction between former and never drinkers in the non-drinking category. But as is shown in [4] failure to do this does not seriously distort the results.
} 
cancer and stroke. The last variable is a physical activity index. Age was also included as a regress or but the survey uses five year age intervals and since all of the analysis involves ten year age intervals there is not enough variation in age within age groups to have any effect on doctor visits. As a result age group was never significant as a variable although doctor visits are much larger in the older age groups.

\section{Probability Models of Doctor Visits}

Most studies which examine the number of times a respondent visits his or her family doctor model this behavior using a count model. Often these models are augmented to take account of excessive zeros. This procedure is now well established and a thorough description of it may be found in [8]. However, an alternative method will be used here. There are a number of reasons for this. First, the data for higher outcomes is not likely to be correct since some respondents appear to be unable to recall the exact number of visits when they report more than six or seven visits. This leads to spikes in the data at 10,15 , and 20 visits so that all of the commonly used count distributions will not fit the data very well. This problem can be circumvented by using a censored count distribution.

There are situations where the data or the type of doctor requires that special treatment be given to the outcomes $\left\{d_{i}=0,1\right\}$ where $d_{\mathrm{i}}$ is the number of visits by respondent $i$. When this is needed two part models like the zip or the hurdle model can be employed. However, visits to Canadian family doctors or general practitioners do not display excessively large or small numbers of zeros. The event $\left\{d_{i}=1\right\}$ is the most common for most male and female age groups but it does not stand out as a candidate for special treatment either. For males aged less than 50 the event $\left\{d_{i}=0\right\}$ is the most likely but this event appears not to pose any problems for fitting statistical models to these age groups.

For reasons involving likelihood criteria and goodness of fit the procedure used here will treat the number of doctor visits in an ordered probability framework with a threshold parameter for each distinct number of visits rather than using a count distribution. In order to minimize the impact of guesswork in the determination of higher order outcomes all outcomes greater than 6 are grouped together as was the case for the censored count model. Unobserved respondent heterogeneity is treated by assuming that there are a finite number of latent classes or types who respond to their characteristics in a specific way. The respondent's characteristics and attributes are described by the vector $Z_{i}$ which is a set of respondent specific variables all of which have been normalized to have a zero mean and unit variance. This means that the size of the estimated coefficient indicates the importance of the regressor associated with it.

The probability that respondent $i$ has $n$ visits is given by

$$
\begin{aligned}
& \operatorname{Pr}\left\{d_{i}=0\right\}=\sum_{j=1}^{J} \pi_{j} \Phi\left(k_{0}-\gamma_{j} Z_{i}\right) \\
& \operatorname{Pr}\left\{d_{i}=n\right\}=\sum_{j=1}^{J} \pi_{j}\left[\Phi\left(k_{n}-\gamma_{j} Z_{i}\right)-\Phi\left(k(n-1)-\gamma_{j} Z_{i}\right)\right]: n=1,2, \cdots 5 \\
& \operatorname{Pr}\left\{d_{i} \geq 6\right\}=\sum_{j=1}^{J} \pi_{j}\left[1-\Phi\left(k_{5}-\gamma_{j} Z_{i}\right)\right]
\end{aligned}
$$

where $\Phi()$ is the cumulative normal distribution function with mean zero and variance one and $\left\{k_{n}: n=0,1, \ldots 5\right\}$ is a set of increasing threshold points. $\gamma_{j} Z_{i}$ is a type specific morbidity or ill-health index and $\mathrm{J}$ is the number of latent classes. As this index increases individuals have more doctor visits the more thresholds they cross. All respondents have the same threshold points but threshold points differ across types by allowing an intercept term for the second and any additional mixture. To identify the model the intercept term for the first mixture is set equal to 0 . The parameters to be estimated are the regression parameters, the type probabilities $\left\{\pi_{j} j=1,2, \ldots J\right\}$ and the threshold parameters.

The number of mixtures to be used is determined by the data. Mixtures are added until there is an increase in the Akaike index function or because the algorithm which maximizes the likelihood function fails to converge. The models that will be estimated here are more complicated than the simple probability model since it is necessary to allow for unobservable effects and for the possibility that not all respondents will react to variables which describe their situation in exactly the same way. Models which allow for this option are called latent class models and are described in [9]. The superiority of this procedure was based on a comparison of models with two latent classes. In this paper five latent classes are used. A similar result was obtained by [10] whose alterna- 
tive to latent class count models was a nonparametric kernel conditional density estimator.

\section{Results}

Parameter estimates for the most important variables for models using 4 or 5 mixtures appear in Table 2(a) and Table 2(b). At most 5 mixtures could be estimated as the maximum likelihood algorithm failed to converge for 6 mixtures. Akaike information criteria support 5 mixture models except for males ages 20 - 29 where 4 is the optimal number. This does not mean that there are only 5 latent classes. There may be more but the data is not rich enough to identify them. As is clear from these two tables, the logarithm of BMI is the most important and significant variable in the explanation of doctor visits for females of all age groups and for males over the age of 50. For males aged 30 - 49 it is the second most important. Only for males aged 20 - 29 is average ln(BMI) not significant. The message that Table 2(a) and Table 2(b) conveys is that obesity is the most important independent factor in determining how often individuals utilize the health care system through their family doctor or a general practice health clinic. And this is the case even when important diseases like diabetes, heart disease, and a large number of other diseases are allowed to play a part in explaining doctor visits. This confirms the cross tabulation results in Table 1 which are not altered when other factors are considered in the determination of doctor visits.

Mixed ordered probability models always outperform mixed censored count models in terms of Vuong's, [11] non-nested criteria. Maximized likelihood function values are much higher for the mixed ordered probability models. They also fit the data better than mixed count models. For the mixed ordered probability models the estimated individual outcome probabilities differ from the actual proportions only at the third or fourth decimal place so that the model fits the data extremely well for all age groups and each gender.

Various smoking and alcohol use variables are also significant as determinants of doctor visits. Both genders are significantly less likely to visit their doctor or a health clinic if they are regular drinkers. This is yet another confirmation of the beneficial effects of moderate alcohol use that have been found in other Canadian studies which look at the relation between alcohol intake and self-reported health, heart disease and diabetes (See [7] and [12]). Respondents who are better educated and higher up the income distribution also have fewer doctor visits.

The results obtained here differ from what [13]-[15] found. These papers use only two mixtures and they do not run separate models by age and gender as is done here. Two mixtures are not sufficient to explain the Canadian data. Two mixtures support a frequent vs. occasional user typology of visits to the doctor. The results here show that the underlying typology is much more complicated and is probably driven by the unobservable duration of obesity. Parameter estimates are sensitive to both age group and gender. Failure to account for this type of variation would produce a typology which is quite different from the one obtained here.

So far the discussion has concentrated on the some of the more technical aspects of the results. Focus turns now to the broader question of the importance of overweight and obesity in terms of its impact on the health care system. Table 3 provides some simple comparisons of the effects of obesity with another major determinant of doctor visits: smoking.

As was suggested in [12] the health impacts of the number of cigarettes smoked per day and BMI were qualitatively very similar in their significant adverse associations with self-reported health, having coronary heart disease or diabetes. The results in this table for doctor visits are even clearer and show that obesity is now significantly more important than smoking in determining the frequency of this type of contact with the health system. For both men and women, individuals who are obese (BMI of at least 30) have more visits to their GP or family doctor than daily smokers. This is evident when daily smokers with BMI less than 25 are compared to non-smokers with BMI of at least 30. For 8 of the 10 age groups the number of doctor visits was more for respondents with a BMI at least thirty than for normal weight daily smokers. The two exceptions are males aged 20 - 29 and females aged $40-49$.

Another way of assessing the impact of obesity on healthcare utilization rates is to ask what proportion of doctor visits is due to obesity. If all individuals were of normal weight then the total number of male doctor visits would be about $9.2 \%$ less than is actually observed. The same number for females is $10.6 \%$. This is a substantial reduction in the use of family doctors that would occur in the hypothetical case if obesity were to disappear from Canadian society. Alternatively, one could also look at the case where everyone had a BMI of thirty or above. This would lead to an increase of about $7.5 \%$ in doctor visits. While both of these cases raise concerns 
Table 2. (a) Maximum likelihood parameter estimates for mixed probability models of doctor visits for males; (b) Maximum likelihood parameter estimates for mixed probability models of doctor visits for females.

(a)

\begin{tabular}{|c|c|c|c|c|c|}
\hline \multirow[t]{2}{*}{ Variable } & \multicolumn{5}{|c|}{ Age Group } \\
\hline & $20-29$ & $30-39$ & $40-49$ & $50-59$ & $60+$ \\
\hline & & Average & Parameter & Estimates & \\
\hline $\ln (\mathrm{BMI})$ & -0.017 & $0.325^{* *}$ & $0.309^{* *}$ & $0.330 * *$ & $0.334 * *$ \\
\hline Married & -0.194 & $0.262^{* *}$ & $0.162^{* *}$ & 0.055 & $0.051 \dagger$ \\
\hline Smoke 1 & -0.022 & $0.232 *$ & $-0.092^{*}$ & 0.00 & 0.013 \\
\hline Smoke 2 & 0.126 & -0.328 & 0.065 & $0.096^{*}$ & $0.068^{* *}$ \\
\hline Smoke 3 & 0.046 & -0.017 & -0.023 & 0.088 & -0.077 \\
\hline Smoke 4 & $0.143^{* *}$ & $0.167 * *$ & -0.003 & $0.191^{* *}$ & $-0.048^{*}$ \\
\hline Smoke 5 & $0.126 \dagger$ & 0.024 & -0.034 & $0.010 \dagger$ & -0.024 \\
\hline Reg. Drink & 0.180 & -0.047 & $-0.216^{* *}$ & $-0.270^{* *}$ & $-0.252^{* *}$ \\
\hline Occ. Drink & -0.188 & $0.207^{* *}$ & $0.145^{* *}$ & -0.038 & -0.028 \\
\hline Education 1 & -0.200 & -0.072 & $-0.201 * *$ & $-0.122^{* *}$ & -0.063 \\
\hline Education 2 & $0.220 \dagger$ & $-0.218^{* *}$ & $-0.113^{* *}$ & $-0.089^{*}$ & -0.088 \\
\hline Education 3 & $0.161^{* *}$ & 0.058 & 0.001 & 0.016 & 0.002 \\
\hline Education 4 & -0.796 & $-0.117^{*}$ & -0.011 & 0.001 & -0.002 \\
\hline Income & 0.204 & -0.006 & -0.121 & $0.654 * *$ & $-0.105^{* *}$ \\
\hline Diabetes & 0.495 & $0.215^{* *}$ & $0.378^{* *}$ & $-0.092 \dagger$ & -0.034 \\
\hline Heart Disease & 0.048 & $-0.143 * *$ & $0.087 \dagger$ & -0.062 & $0.060 * *$ \\
\hline Other Diseases & 0.042 & $0.128^{* *}$ & $0.247^{* *}$ & 0.062 & 0.013 \\
\hline \multirow[t]{2}{*}{ Physical Activity } & 0.057 & $0.128^{* *}$ & 0.061 & -0.081 & 0.007 \\
\hline & & Type & BMI & Estimates & \\
\hline Type 1 BMI & $1.084^{* *}$ & $-0.515^{* *}$ & $-0.560 * *$ & $0.381^{* *}$ & $0.498^{* *}$ \\
\hline Type 2 BMI & $-0.227 * *$ & $0.933^{* *}$ & $0.753^{* *}$ & $0.127^{*}$ & $-0.604^{* *}$ \\
\hline Type 3 BMI & -0.630 & $-0.266 \dagger$ & $0.282^{*}$ & -0.082 & $0.171^{* *}$ \\
\hline Type 4 BMI & $0.258 *$ & $0.365^{* *}$ & $0.599 * *$ & $1.789 * *$ & $0.827^{* *}$ \\
\hline \multirow[t]{2}{*}{ Type 5 BMI } & - & $0.779 * *$ & $0.561^{* *}$ & $0.174 \dagger$ & $0.265^{* *}$ \\
\hline & & Type & Probability & Estimates & \\
\hline$\pi_{1}$ & $0.183^{* *}$ & $0.169 * *$ & $0.109 * *$ & $0.102 * *$ & $0.350 * *$ \\
\hline$\pi_{2}$ & $0.295^{* *}$ & $0.223^{* *}$ & $0.159 * *$ & $0.156^{* *}$ & $0.089 * *$ \\
\hline$\pi_{3}$ & $0.303^{* *}$ & $0.186 * *$ & $0.201^{* *}$ & $0.292 * *$ & $0.206^{* *}$ \\
\hline$\pi_{4}$ & $0.219 * *$ & $0.180^{* *}$ & $0.246 * *$ & $0.096^{* *}$ & $0.150 * *$ \\
\hline$\pi_{5}$ & - & $0.241^{* *}$ & $0.284^{* *}$ & $0.354 * *$ & $0.205^{* *}$ \\
\hline Sample Size & 3526 & 3488 & 3848 & 4606 & 8287 \\
\hline
\end{tabular}


(b)

\begin{tabular}{|c|c|c|c|c|c|}
\hline \multirow[t]{2}{*}{ Variable } & \multicolumn{5}{|c|}{ Age Group } \\
\hline & $20-29$ & $30-39$ & $40-49$ & $50-59$ & $60+$ \\
\hline & & Average & Parameter & Estimate & \\
\hline $\ln (\mathrm{BMI})$ & $0.305^{* *}$ & $0.458 * *$ & $0.331 * *$ & $0.433^{* *}$ & $0.427 * *$ \\
\hline Married & $0.104^{* *}$ & $0.190 * *$ & $0.140^{* *}$ & 0.044 & $-0.087 * *$ \\
\hline Smoke 1 & 0.038 & $-0.188^{* *}$ & $0.328^{* *}$ & $0.389 * *$ & $0.080^{* *}$ \\
\hline Smoke 2 & 0.049 & 0.006 & $-0.108 \dagger$ & $0.161^{* *}$ & 0.031 \\
\hline Smoke 3 & 0.062 & 0.025 & -0.053 & $0.171^{* *}$ & $-0.116^{*}$ \\
\hline Smoke 4 & $0.139 * *$ & $0.164^{* *}$ & $0.166^{* *}$ & $0.276^{* *}$ & $0.128 * *$ \\
\hline Smoke 5 & $0.169 * *$ & $0.151^{* *}$ & 0.052 & $0.148^{* *}$ & -0.031 \\
\hline Reg. Drink & $-0.248^{* *}$ & $-0.256 \dagger$ & $-0.204^{* *}$ & $-0.241^{* *}$ & $-0.130 * *$ \\
\hline Occ. Drink & -0.039 & 0.112 & 0.080 & -0.036 & -0.002 \\
\hline Education 1 & $-0.187 * *$ & $-0.332 * *$ & $-0.215^{* *}$ & -0.006 & $-0.098 *$ \\
\hline Education 2 & $-0.223^{* *}$ & $-0.157 * *$ & -0.020 & $-0.096 * *$ & $-0.074 *$ \\
\hline Education 3 & $0.078 \dagger$ & $0.158^{* *}$ & -0.017 & -0.008 & $0.068 * *$ \\
\hline Education 4 & -0.084 & $0.121^{*}$ & 0.032 & 0.042 & $-0.060 \dagger$ \\
\hline Income & 0.025 & $-0.314 * *$ & $-0.303 * *$ & $-0.177 \dagger$ & $-0.119 * *$ \\
\hline Diabetes & $0.178^{* *}$ & 0.052 & -0.046 & $0.063 \dagger$ & -0.027 \\
\hline Heart Disease & $-0.205^{* *}$ & $-0.132 * *$ & -0.052 & -0.009 & 0.037 \\
\hline Other Diseases & $0.121^{* *}$ & 0.014 & 0.002 & 0.007 & 0.009 \\
\hline \multirow[t]{2}{*}{ Physical Activity } & 0.068 & 0.064 & 0.007 & 0.015 & -0.027 \\
\hline & & Type & BMI & Estimate & \\
\hline Type 1 BMI & $0.757^{* *}$ & $1.255^{* *}$ & 0.079 & $0.184^{*}$ & $0.219 *$ \\
\hline Type 2 BMI & $0.739 * *$ & $0.165 \dagger$ & $1.066^{* *}$ & $1.033^{* *}$ & $0.399 * *$ \\
\hline Type 3 BMI & $0.607 * *$ & $1.688^{* *}$ & $0.324^{* *}$ & 0.144 & $-0.287^{* *}$ \\
\hline Type 4 BMI & $-1.179 * *$ & $0.365^{* *}$ & 0.062 & $-0.236^{*}$ & $2.896 * *$ \\
\hline \multirow[t]{2}{*}{ Type 5 BMI } & $0.162 *$ & $0.779 * *$ & -0.092 & $0.826^{* *}$ & $0.708^{* *}$ \\
\hline & & Type & Probability & Estimate & \\
\hline$\pi_{1}$ & $0.130 * *$ & $0.180 * *$ & $0.140 * *$ & $0.264 * *$ & $0.151^{* *}$ \\
\hline$\pi_{2}$ & $0.244^{* *}$ & $0.366^{* *}$ & $0.779 * *$ & $0.111^{* *}$ & $0.535^{* *}$ \\
\hline$\pi_{3}$ & $0.254^{* *}$ & $0.142^{* *}$ & $0.371^{* *}$ & $0.178^{* *}$ & $0.189^{* *}$ \\
\hline$\pi_{4}$ & $0.140 * *$ & $0.132 * *$ & $0.144^{* *}$ & $0.118^{* *}$ & $0.066^{* *}$ \\
\hline$\pi_{5}$ & $0.233^{* *}$ & $0.180^{* *}$ & $0.168^{* *}$ & $0.329 * *$ & $0.059 * *$ \\
\hline Sample size & 3760 & 3978 & 3885 & 5345 & 11432 \\
\hline
\end{tabular}

notes: $\uparrow, *$, and $* *$ indicate significant at the 10,5 , and 1 percent levels. The average effect is $\sum \pi_{j} \gamma k_{j}$ for variable $k$. 
Table 3. Doctor visits by type of smoker, BMI category, age group, and gender (standard error).

\begin{tabular}{|c|c|c|c|c|c|}
\hline Age Group & Smoking Category & Normal Males & Obese Males & Normal Females & Obese Females \\
\hline & \multicolumn{5}{|c|}{ Doctor Visits } \\
\hline \multicolumn{6}{|l|}{ Age Group } \\
\hline \multirow{2}{*}{$20-29$} & Never Smoker & $1.293(0.086)$ & $1.312(0.136)$ & $2.733(0.106)$ & $3.801(0.360)$ \\
\hline & Daily Smoker & $1.855(0.167)$ & $1.803(0.249)$ & $3.677(0.232)$ & $4.462(0.478)$ \\
\hline \multirow{2}{*}{30 - 39} & Never Smoker & $1.792(0.169)$ & $2.113(0.189)$ & $2.745(0.107)$ & $3.667(0.283)$ \\
\hline & Daily Smoker & $1.778(0.172)$ & $2.412(0.322)$ & $3.307(0.244)$ & $5.069(0.510)$ \\
\hline \multirow{2}{*}{$40-49$} & Never Smoker & $1.716(0.163)$ & $2.446(0.202)$ & $2.287(0.090)$ & $3.504(0.275)$ \\
\hline & Daily Smoker & $2.208(0.165)$ & $3.786(0.388)$ & $3.784(0.260)$ & $4.834(0.440)$ \\
\hline \multirow{2}{*}{$50-59$} & Never Smoker & $1.997(0.151)$ & $3.000(0.221)$ & $2.708(0.120)$ & $3.600(0.170)$ \\
\hline & Daily Smoker & $2.557(0.182)$ & $3.449(0.234)$ & $3.254(0.193)$ & $4.394(0.302)$ \\
\hline \multirow{2}{*}{$60+$} & Never Smoker & $3.279(0.152)$ & $3.926(0.238)$ & $3.368(0.078)$ & $4.112(0.136)$ \\
\hline & Daily Smoker & 3.206 (0.198) & $4.696(0.198)$ & 4.499 (0.198) & $4.224(0.296)$ \\
\hline
\end{tabular}

about the seriousness of obesity the situation in Canada involving the use of medical services by individuals who are overweight or obese has not yet reached the stage that some of the literature referred to earlier describes as catastrophic or of epidemic proportion. Canadian health services are not going to be crushed by the weight of it users now or in the near future. Nor is the disappearance of the obese going to solve the current problems involving wait times and the shortage of GPs.

While the situation concerning the utilization of physician services may not be as critical as is sometimes claimed the application of these simple conceptual experiments to diabetes produces results which are much more alarming. If obesity disappeared and everyone was of normal weight there would be $43.3 \%$ fewer cases of diabetes in men and 53.8\% fewer in women. On the other hand if everyone were obese this would lead to an 83.4\% increase in male diabetes cases and a $123.2 \%$ increase in female diabetes cases.

Obesity is a serious problem. It has now overtaken smoking as the leading cause of doctor visits and, as was the case for tobacco use, a national coordinated policy is needed to deal with it.

\section{Conclusions}

To summarize the study's main results, for most age groups obesity is the most important explanatory variable in the determination of doctor visits for men. Both genders having a BMI of at least 30 lead to significantly more doctor visits than being a daily smoker. Individuals who smoke, have diabetes and heart disease, are inactive, come from the lower part of the income distribution, or are poorly educated are also more likely to visit their doctor.

Unobserved characteristics play an important role in determining who visits their doctor. The presence of genetic characteristics and various dimensions of behavior and obesity history that are unobservable to the researcher affect how often individuals visit their doctor and require a special statistical procedure. Latent class's ordered probability models are used to explain doctor visits and allow different individuals to respond differently to the observable variables which describe their situation because of these unobservable effects. This procedure is quite different from the methodology that is usually used in the analysis of doctor visit and it is preferred on likelihood criteria over methods involving counts. The reason why the importance of BMI differs across types is due to timing of obesity and the variation in individual BMI histories. Many research papers based on longitudinal data show that both the degree of the individual's overweight as well as its duration have an impact on the risks of insulin resistance, impaired glucose tolerance, and type 2 diabetes, as noted by [16]. Current BMI is a good representation of historical BMI for some respondents but not for others. Individuals whose increase in BMI was fairly recent may not yet be paying the full price of being overweight or obese. The effects of obesity on health do not occur immediately; they appear with lags that can be quite long and possibly vary with the individual [17]. For types whose weight gains are recent the association between doctor visits and ln(BMI) could very well be negative. 
There are limitations about what can be learned about the effects of excess weight on both health and health service utilization rates from surveys like the Canadian Community Health Survey. This survey does not collect much retrospective information. Having data on the respondent's weight history is a much better alternative to a statistical procedure which attempts to control for the variation in age at first obesity. BMI is a widely used measure of being overweight or obese. But many studies have shown that the location of adipose tissue is also important in determining health risks. This information is easy to collect and it is probably time for Statistics Canada to design a survey which is exclusively devoted to assessing the population's physical characteristics and health histories as they relate to the obesity problem.

\section{Acknowledgements}

The author benefited from discussions with Peter R. Weldon and Logan McLeod. This paper was presented at the 2012 Canadian Economic Association Meetings in Calgary; thanks go to the discussant, Pierre-Karl Michaud, for helpful comments.

\section{References}

[1] Public Health Agency of Canada and Canadian Institute for Health Information Canada (2011) Obesity in Canada. Queens Printer, Ottawa.

[2] Peeters, A., Barendregt, J.J., Willekens, F., Mackenbach, J.P., Mamum, A.A. and Bonneux, L. (2010) Obesity in Adulthood and Its Consequences for Life Expectancy: A Life-Table Analysis. Annals of Internal Medicine, 138, $24-32$.

[3] Statistics Canada (2013) Canadian Community Health Survey, 2011-2012. [Machine Readable Data File]. Ottawa, ON.

[4] Trakas, K., Lawrence, K. and Shear, N.H. (1999) Utilization of Health Care Resources by Obese Canadians. Canadian Medical Association Journal, 160, 1457-1462.

[5] Dunlop, S., Coyte, P.C. and McIsaac, W. (2000) Socio-Economic Status and the Utilisation of Physicians' Services: Results from the Canadian National Population Health Survey. Social Science and Medicine, 51, 123-133. http://dx.doi.org/10.1016/S0277-9536(99)00424-4

[6] Curtis, L.J. (2006) Snapshots of Health-Care Utilization in Canada: Is the Picture Changing? 1978-1998. In: Beach, C.M., Chaykowski, R.P., Shortt, S., St-Hilaire, F. and Sweetman, A., Eds., Health Services Restructuring in Canada: New Evidence and New Directions, McGill-Queens University Press, Kingston, Ontario.

[7] McIntosh, J. (2008) Is Alcohol Consumption Good for You? Results from the 2005 Canadian Community Health Survey. Addiction Research and Theory, 16, 553-563. http://dx.doi.org/10.1080/16066350802011631

[8] Winkelmann, R. (2008) Econometric Analysis of Count Data. 5th Edition, Springer-Verlag, Berlin.

[9] Cameron, A.C. and Trivedi, P.K. (2005) Microeconometrics, Methods and Applications. Cambridge University Press, Cambridge.

[10] McLeod, L. (2011) A Nonparametric vs. Latent Class Model of General Practitioner Utilization: Evidence from Canada. Journal of Health Economics, 30, 1261-1279. http://dx.doi.org/10.1016/j.jhealeco.2011.08.005

[11] Vuong, Q.H. (1989) Likelihood Ratio Tests for Model Selection and Non-Nested Hypotheses. Econometrica, 57, 307333. http://dx.doi.org/10.2307/1912557

[12] MacMinn, W., McIntosh, J. and Yung, C. (2007) How Much Does Obesity Matter? Results from the 2001 Canadian Community Health Survey. Advances in Health Economics and Health Services Research: The Economics of Obesity, 17, 333-364. http://dx.doi.org/10.1016/S0731-2199(06)17013-2

[13] Gupta, N.D. and Greve, J. (2011) Overweight and Obesity and the Utilization of Primary Care Phyicians. Health Economics, 20(S1), 53-67. http://dx.doi.org/10.1002/hec.1711

[14] D’Uva, T.B. (2006) Latent Class Models for Utilization of Health Care. Health Economics, 15, 329-343. http://dx.doi.org/10.1002/hec.1112

[15] Deb, P. and Trivedi, P.K. (1997) Demand for Medical Care by the Elderly: A Finite Mixture Approach. Journal of Applied Econometrics, 12, 313-336.

[16] Black, E., Holst, C., Astrup, A., Toubro, S., Echwalt, S., Petersen, O. and Sørensen, I.A. (2005) Long Term Influences of Body-Weight Changes, Independent of the Attained Weight, on Risk of Impaired Glucose Tolerance and Type 2 Diabetes. Diabetic Medicine, 22, 1199-1205. http://dx.doi.org/10.1111/j.1464-5491.2005.01615.x

[17] Kopelman, P.G. (2000). Obesity as a Medical Problem. Nature, 404, 635-642. 
Scientific Research Publishing (SCIRP) is one of the largest Open Access journal publishers. It is currently publishing more than 200 open access, online, peer-reviewed journals covering a wide range of academic disciplines. SCIRP serves the worldwide academic communities and contributes to the progress and application of science with its publication.

Other selected journals from SCIRP are listed as below. Submit your manuscript to us via either submit@scirp.org or Online Submission Portal.
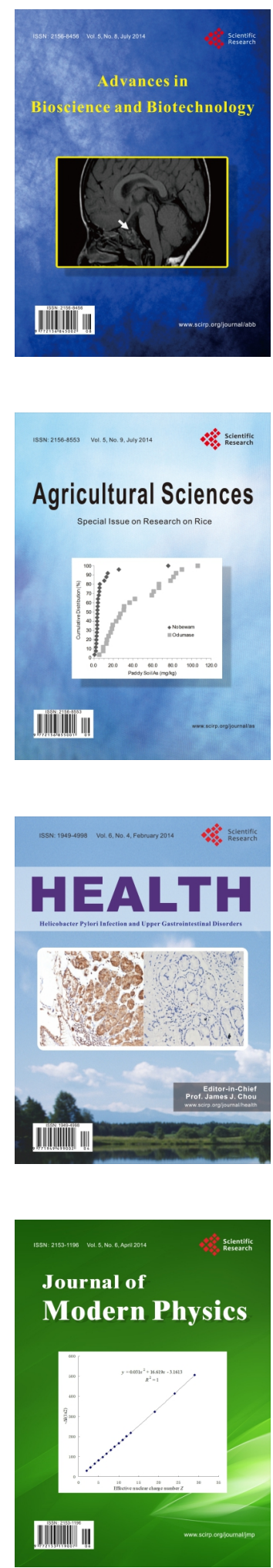
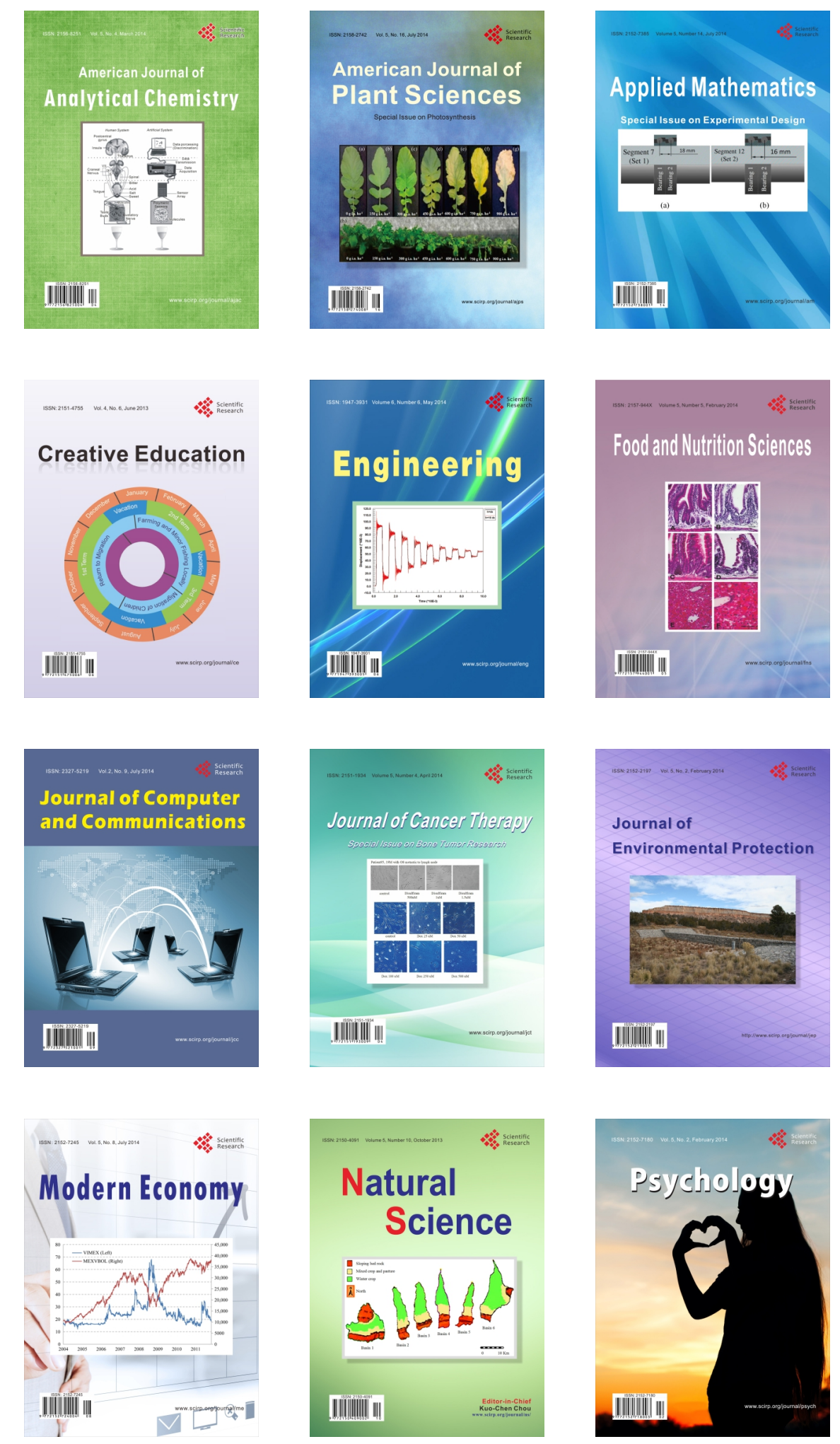